\title{
Diagnóstico laboratorial do albinismo oculocutâneo
}

\author{
Laboratory diagnosis of oculocutaneous albinism
}

Luciane de Melo Rocha', Lilia Maria de Azevedo Moreira²

\begin{abstract}
unitermos
Albinismo oculocutâneo

resumo

OCA 1

Objetivo: Avaliar os métodos laboratoriais dos diferentes tipos de albinismo oculocutâneo (OCA 1 e OCA 2) de forma descritiva e analisar sua eficiência. Material e método: O teste do bulbo capilar é um

OCA 2 método químico usado para distinguir as duas formas, no entanto recentemente teve sua eficácia como

Teste do bulbo capilar teste padrão contestada. $\mathrm{O}$ avanço da biologia molecular permite a análise das mutações que causam

Teste do bulbo capilar o distúrbio e a sua localização gênica. Conclusão: O teste do bulbo é seguro apenas para o diagnóstico

Genética molecular do OCA 1A, podendo ser usado como complemento de um método mais apurado. A análise molecular fornece um diagnóstico definitivo, permitindo distinguir OCA 1 de OCA 2, pois as mutações afetam genes em cromossomos diferentes.
\end{abstract}

Objectives:To evaluate the laboratories methods of the oculocutaneous albinism (OCA 1 and OCA 2) of descriptive form and to analyze its results. Methods: The hair bulb test is a chemical method used to distinguish the two forms, however, recently had its effectiveness as an standard test contested. The advance of molecular biology allows the analysis of the mutations that cause the disturb and its genic location. Conclusions: The bulb test is secure only for the diagnosis of OCA 1A, being able to be used as complement of a more refined method. The molecular analysis supplies a diagnostic definitive allowing to distinguish OCA 1 from OCA 2, because the mutations affect genes in different chromosomes.

\section{key words}

Oculocutaneous albinism

OCA 1

OCA 2

Hair bulb test

Molecular genetics

\section{Introdução}

O albinismo é um distúrbio de natureza genética em que há redução ou ausência congênita do pigmento melanina. O principal tipo de albinismo é o oculocutâneo (OCA), caracterizado pela ausência total ou parcial de pigmento. A melanina é sintetizada por melanócitos, células dendríticas localizadas na junção da derme com a epiderme da pele, através de reações enzimáticas que convertem a tirosina em melanina através da enzima tirosinase ${ }^{(22)}$. Durante o desenvolvimento embrionário, as células precursoras de melanina (melanoblastos) mi- gram para o topo neural da pele, os folículos capilares e a úvea dos olhos ${ }^{(22)}$. Assim, são diretamente responsáveis pela característica de cor. Embora a síntese de pigmentos ocorra dentro dos melanócitos, a maioria dos pigmentos da pele é encontrada em vesículas cheias de melanina, conhecidas como melanossomos, localizadas dentro de células chamadas de queratinócitos ${ }^{(22)}$.

Melanossomos são organelas semelhantes aos lisossomos produzidos pelo complexo golgiense e pelo retículo endoplasmático rugoso, que os tornam maduros e pigmentados. Em seguida são transportados por

1. Graduanda em Farmácia pela Universidade Federal da Bahia (UFBA).

2. Professora-titular de Cenética do Instituto de Biologia da UFBA. 
processos dendríticos e encaminhados para queratinócitos adjacentes $^{(22)}$. O pH dentro dos melanossomos é de fundamental importância para regular a atividade da tirosinase. Provavelmente, a proteína de membrana melanossômica responsável pela neutralização do $\mathrm{pH}$ é a P-proteína ${ }^{(22)}$. Acredita-se que ela funcione como um canal que reduz a concentração de prótons dentro do melanossomos ${ }^{(2,22)}$. Ao corar células humanas com uma solução fracamente fluorescente, é possível perceber que o $\mathrm{pH}$ de melanossomos de melanócitos brancos é ácido, enquanto que nos negros são mais neutros ${ }^{(5,22)}$. Isso sugere que ambientes ácidos causam redução da atividade da tirosinase ${ }^{(5,22)}$.

\section{Classificação do albinismo}

O albinismo é classificado em:

- ocular - quando somente os olhos sofrem despigmentação; - parcial - o organismo produz melanina na maior parte do corpo, mas em outras partes isso não ocorre;

- oculocutâneo - todo corpo é afetado. O bloqueio da síntese de melanina é completo no tipo OCA 1 (albinismo oculocutâneo tirosinase-negativo) e seus olhos, cabelos e pele não desenvolvem nenhum pigmento ${ }^{(4,8)}$. Nos outros tipos o bloqueio não é completo e uma quantidade variável de melanina é formada, podendo haver nos indivíduos afetados escurecimento dos cabelos e desenvolvimento de pigmento na íris com a idade ${ }^{(8)}$. O OCA 1 é ainda dividido em OCA 1A e OCA 1B, sendo o primeiro a mais severa forma de $O C A^{(5)}$. O nível de tirosinase é bastante reduzido no OCA $1 \mathrm{~B}$, mas não ausente ${ }^{(5)}$. O OCA 2 (albinismo oculocutâneo positivo) é o tipo de albinismo mais comum ${ }^{(4,11)}$.

\section{Síntese de melanina}

Podem ser formados dois tipos de melanina: a feomelanina (amarela e vermelha) e a eumelanina (preta e marrom). A formação de algum pigmento em albinos com certos tipos de OCA sugere que a feomelanina é a primeira a ser formada, surgindo a eumelanina muito tempo depois ${ }^{(8)}$. Culturas de melanócitos em indivíduos de peles clara e escura demonstraram que a atividade catalítica da tirosinase na eumelanina é maior quando comparada à da feomelanina ${ }^{(8,22)}$. Entretanto, apesar dessa diferença, a quantidade da enzima é a mesma ${ }^{(7,}$ 22). O pH melanossômico provavelmente está envolvido no controle da atividade da enzima ${ }^{(6,21)}$. Outras proteínas de membrana envolvidas nas diferenças entre as duas melaninas são a proteína silver (SILV), a proteína 1 relacionada à tirosinase (TRP1) e a TRP2. Essas duas últimas são encontradas apenas em eumelanossomos ${ }^{(22)}$.
A enzima tirosinase é responsável pela hidroxilação da tirosina à 3,4-diidroxifenilalanina (Dopa) e pela oxidação da Dopa em dopaquinona ${ }^{(5,9,10,20,22)}$. A eumelanina é derivada da dopacromo, enquanto a feomelanina deriva do metabolismo da 5-S-cisteína-Dopa ${ }^{(4,9,2)}$. No eumelanossomo ocorre a isomerização da dopacromo em ácido 5,6-diidroxindol-2carboxílico (Dhica) pela enzima dopacromo tautomerase, e a oxidação da Dhica é realizada pela Dhica-oxidase ${ }^{(4,5,22)}$ (Figura 1). Portadores de albinismo oculocutâneo não conseguem oxidar a tirosina em Dopa através da tirosinase ${ }^{(10)}$.

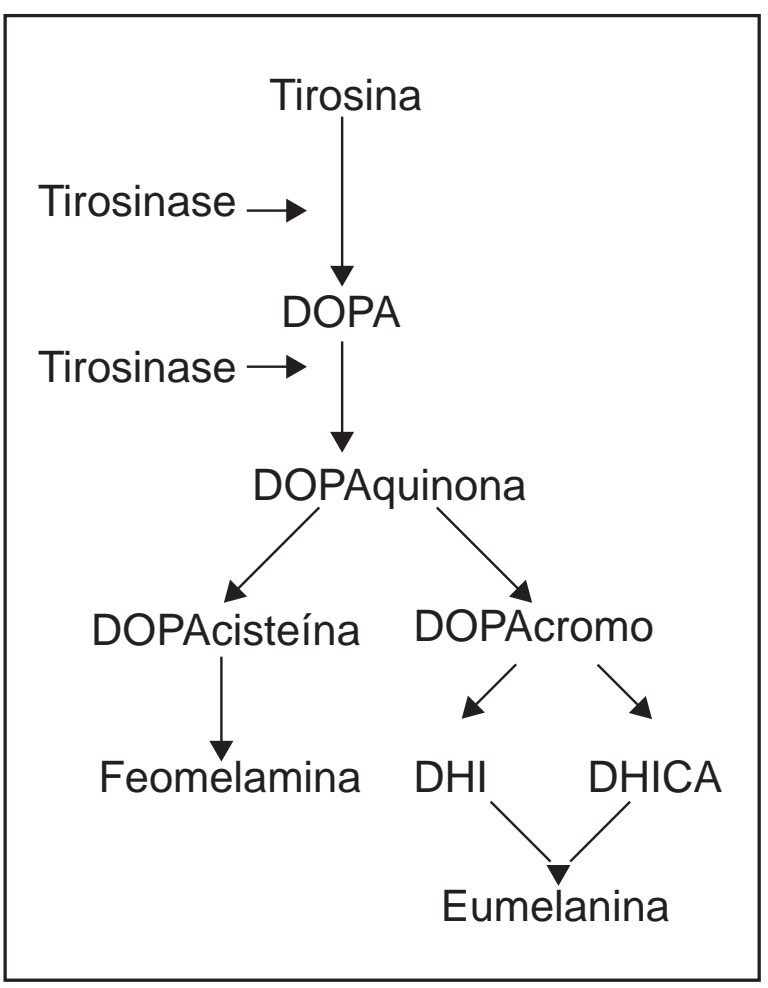

Figura 1 - Biossíntese de melanina

\section{Diagnóstico clínico}

Os albinos são praticamente incapazes de transformar a tirosina em melanina. Conseqüentemente, têm a pele muito clara, cabelos brancos ou claros e seus olhos são vermelhos, pois a luz refletida atravessa os vasos sangüíneos dos olhos, ou, ainda, azul-esverdeados, se houver formação de algum pigmento na íris ${ }^{(21)}$. Possuem fotofobia, astigmatismo, miopia, além de outros distúrbios visuais ${ }^{(4,5,20)}$.

\section{Frequiência nas populações}

Diversas pesquisas sobre o albinismo mostram que a característica está presente em todas as etnias, embora tenha uma prevalência aumentada entre negros. É estimado que 
uma em 17 mil pessoas tenha um dos tipos de albinismo(4). O OCA 1 atinge aproximadamente um em 40 mil indivíduos na maioria das populações ${ }^{(4)}$. A freqüência de OCA 2 nos EUA é de um em 36 mil(12); um em 10 mil nos negros afro-americanos e um em 1.100 na população nigeriana em geral(16).

\section{Detecção de OCA 1 e OCA 2}

Clinicamente é difícil distinguir entre as duas formas de albinismo oculocutâneo. O albino tirosinase-positivo pode desenvolver uma melhor acuidade visual na idade adulta, sendo essa a melhor forma de uma possível distinção entre os dois tipos de albinismo(4). A heterogeneidade das formas de albinismo oculocutâneo foi evidenciada em um estudo realizado por Trevor-Roper(23), depois que pais albinos tiveram crianças normais, apontando a existência de dois loci distintos ${ }^{(17)}$. Como há diferença no condicionamento genético dos subtipos de albinismo, casais albinos podem ter filhos com pigmentação normal. Nesse caso, para o aconselhamento genético é necessária a identificação correta da forma de albinismo.

O objetivo do presente trabalho é descrever os principais métodos de análise que diferenciam o albinismo oculocutâneo positivo do negativo.

\section{Material e método}

\section{Teste do bulbo capilar}

As diferenças entre OCA 1 e OCA 2 foram evidenciadas por métodos químicos, como o teste do bulbo capilar. Esse teste parte do princípio de que albinos oculocutâneo positivos, ao contrário dos negativos, produzem certa quantidade de melanina.

Bulbos capilares são usados como fonte de melanóci$\operatorname{tos}^{(10)}$. A atividade catalítica da tirosina é determinada pela incubação com Dopa ou tirosina e conseqüente indução da síntese de melanina verificada pela inspeção visual ou por ensaios bioquímicos ${ }^{(5)}$. As amostras dos albinos tirosinasepositivos produzem pigmentos visíveis ao microscópio, como demonstrado na Figura 2, enquanto os tirosinasenegativos não os produzem ${ }^{(10,11)}$.

\section{Material}

- Incubação na solução de L-tirosina:

- oito a 10 bulbos de cabelo de cada paciente;

- $1 \mathrm{mg} / \mathrm{ml}$ de L-tirosina em 0,1 fosfato, $\mathrm{pH} 6,8$;

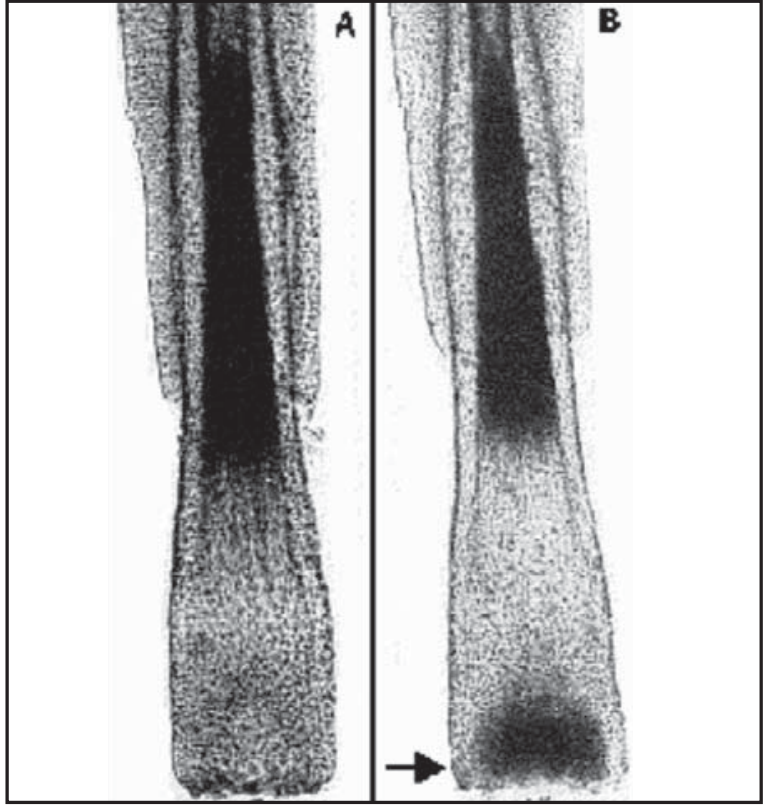

Figura 2 - Raiz de cabelo de indivíduo albino evidenciando a diferença entre OCA 1 e OCA 2. 0 detalhe mostra a produção de melanina em tirosinase-positivo. Aumento de $56 x^{(11)}$

- 0,01 M de dietioditiocarbamato de sódio adicionado à solução;

- 0,01 M de 4-clororesorcinol adicionado à solução;

- microscópio com aumento de 80x.

\section{Procedimento}

Os fios de cabelo são colhidos com um único puxo, fazendo uso de um pequeno alicate odontológico. A seguir são separados, identificados e, então, cortados e levados para análise ${ }^{(10)}$. A incubação de cada fio é feita separadamente numa solução contendo L-tirosina a $37^{\circ}$ por 24 horas $^{(11)}$. Após a incubação, os bulbos são lavados em água destilada, colocados em lâminas de vidro e observados ao microscópio com aumento de $80 \mathrm{x}^{(11)}$.

- Incubação na solução de L-Dopa:

- oito a 10 bulbos de cada paciente;

- $1 \mathrm{mg} / \mathrm{ml}$ de L-Dopa em 0,1 fosfato, pH 7,4.

\section{Procedimento}

A diferença entre esta solução e a da L-tirosina, é que a incubação na L-DOPA é feita por 5 horas e não são adicionados os inibidores da tirosinase, dietioditiocarbamato de sódio e 4-clororesorcinol. Essa solução é usada para deter- 
minar se os bulbos que não apresentaram atividade com a tirosina podem revelar algum resultado com Dopa ${ }^{(11)}$.

O teste do bulbo foi descrito na década de 1970. Sua análise é qualitativa, e não quantitativa. Quando se quer comparar a atividade da tirosinase em indivíduos heterozigotos com controles, é feita uma análise quantitativa medindo a quantidade de água formada na oxidação da tirosina em Dopa. Atualmente, embora essa técnica seja usualmente referida como sensível na diferenciação das duas formas de albinismo oculocutâneo, é verificada a ocorrência de falsos positivos e negativos, não sendo geralmente utilizada como método único(5).

\section{Análise molecular da sequuência gênica}

Com o avanço da biologia molecular foi possível localizar os genes nos quais ocorrem as mutações nos diferentes tipos de albinismo. A tecnologia dos marcadores genéticos tornou possível o mapeamento genético de doenças hereditárias e, assim, saber a localização cromossômica de doenças mendelianas. Um gene pode, então, ser ampliado pela tecnologia de reação em cadeia da polimerase (PCR) e, daí, ter sua seqüência nucleotídica desejada ${ }^{(18)}$. Comparando essa seqüência com a de um indivíduo afetado, é possível conhecer as mutações ocorridas e como elas afetam a produção da enzima ou proteína.

A definição do locus gênico em que ocorre a mutação é importante para caracterizar o tipo de albinismo. A mutação no locus TYR, que está no cromossomo 11 (11q14-q21) (3-5, 15, 22), afeta a produção da tirosinase e ocorre OCA $1^{(1,4,5,15,22)}$. No entanto, quando a alteração ocorre no locus OCA 2, localizado no cromossomo $15(15 q 11,2-q 12)^{(14,19)}$, a proteína afetada é a P-proteína e o indivíduo tem OCA $2^{(1,4,5,22)}$. Como já dito anteriormente, essa proteína controla o pH melanossômico, fundamental para a atividade da tirosinase.
A estratégia de análise usada por um laboratório de genética brasileiro para o albinismo oculocutâneo positivo é a análise de mutação ${ }^{(7)}$. Para o negativo é feito o seqüenciamento de todos os cincos éxons envolvidos.

\section{Métodos}

\section{Preparação do DNA genômico}

Amostras de sangue são coletadas dos pacientes e os linfócitos, isolados por lise osmótica ${ }^{(13,15)}$. Depois de lisados, são incubados com $75 \mu \mathrm{g} / \mathrm{ml}$ de proteinase $\mathrm{K}$ a $60^{\circ} \mathrm{C}$ por toda uma noite ${ }^{(15)}$. O DNA é isolado por extração da fase aquosa com fenol e clorofórmio, sendo por fim precipitado com etanol ${ }^{(15)}$. O DNA é cortado com Taq I a $65^{\circ} \mathrm{C}$, separado por gel de agarose e analisado com Southern blotting ${ }^{(15)}$. Os fragmentos desejados são obtidos através de sondas, que são seqüências nucleotídicas complementares marcadas com material fluorescente ${ }^{(15)}$. Para amplificação do DNA é realizada a técnica de $\mathrm{PCR}^{(15)}$. Os primers sintetizados são analisados em comparação com a seqüência normal conhecida de nucleotídeos. Assim é possível verificar qual ou quais bases foram trocadas e que aminoácidos foram gerados.

\section{Análise das seqüências}

Em um estudo feito por Oetting et al. ${ }^{(15)}$, foi obtido o seqüenciamento molecular de três indivíduos com OCA 1 de uma mesma família, sendo que dois eram gêmeos. Os três apresentaram uma mutação do tipo sem sentido no códon 81 (Pro $\rightarrow$ Leu) dentro do éxon 1. Os gêmeos tiveram uma segunda mutação no códon 371 (Asn $\rightarrow$ Thr) dentro do éxon 3 e o terceiro indivíduo teve uma segunda mutação no códon 47 (Gli $\rightarrow$ Asp). Portanto foram necessárias duas diferentes mutações para resultar na perda da função da enzima $^{(15)}$, como mostrado na Figura 3.

Terceiro indivíduo:

Códon 47 Normal 5' CCCTGTGGCCAGCTT 3'

Códon 47 Mutante 5 ' ----------GAC---------- 3'

Códon 81 5' TCGTGGCCTTCCGTC 3'

Códon 81 5' ----------CTT---------- 3'

Gêmeos:

Códon 371 Normal 5' TATATGAATGGAACA 3'

Códon 371 Mutante 5' ---------

Códon 81

5' TCGTGGCCTTCCGTC 3'

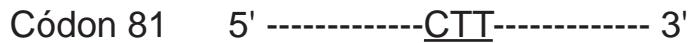

Figura 3 - Mutações encontradas nos três albinos estudados por Oetting et al. No terceiro indivíduo os aminoácidos CLI e PRO foram trocados por ASP e LEU, respectivamente Nos gêmeos, os aminoácidos PRO e ASN foram trocados por LEU e THR ${ }^{(15)}$ 


\section{Discussão e conclusão}

O teste do bulbo piloso diferencia o OCA 1 do OCA 2. Este ensaio pode ser utilizado para identificar o OCA 1 A com segurança. Entretanto, um resultado positivo mostra a possibilidade de outros tipos de albinismo como OCA 1B, OCA 2, OCA 3 ou $A O 1^{(3,5)}$. A confirmação dessas outras formas de albinismo é obtida com segurança pelo seqüenciamento das mutações. Como os genes que codificam as proteínas envolvidas nas formas de OCA estão em cromossomos diferentes, apenas a localização cromossomial das mutações teoricamente já seria suficiente para distinguir as duas variações.

Portanto, os albinos tirosinase-positivos produzem certa quantidade de melanina não porque têm o gene da tirosinase afetado, e sim devido ao funcionamento incorreto da enzima que regula o pH. Ou seja, a enzima é ativa, entretanto não tem um meio adequado para funcionar, enquanto os negativos não produzem nenhuma melanina devido ao total comprometimento da tirosinase.
Os avanços nas técnicas de seqüenciamento molecular proporcionam a identificação dos cromossomos envolvidos nas diferentes formas de albinismo, assim como informações sobre as mutações presentes. Essas informações possibilitam uma melhor compreensão do distúrbio e futuras possibilidades de melhoria nas condições de vida dos albinos, uma vez que o conhecimento preciso das suas causas é uma condição para a elaboração de técnicas mais eficazes de prevenção e tratamento. Os resultados proporcionados pela análise molecular configuram-se como os mais adequados, já que apontam os genes que ocorrem nas mutações e a natureza dessas mutações.

\section{Agradecimentos}

As autoras agradecem ao dedicado apoio de lago Teles Dominguez Cabanelas, bolsista do Programa Institucional de Bolsas de Iniciação Científica e do Conselho Nacional de Desenvolvimento Científico e Tecnológico (PIBIC/CNPq), na preparação final do artigo.

\section{Referências}

I. ALALUF, S. et al. Ethnic variation in tyrosinase and TYRP | expression in photoexposed and photoprotected human skin. Pigment Cell Res, v. I6, n. I, p. 35-42, 2003.

2. ANCANS, J.; HOOGDWIJN, M. J.; THODY, A. J. Melanosomal $\mathrm{pH}$, pink locus protein and their roles in melanogenesis. J InvestDermatol, v. I 17, n. 2, p. 158-9, 2001.

3. BARTON, D. E.; KWON, B. S.; FRANCKE, U. Human tyrosinase gene, mapped to chromosome II (q|4-q2I), defines second region of homology with mouse chromosome 7. Genomics, v. 3, p. 17-24, 1988

4. BASHOUR, M.; HASSANEE, K.;AHMED, I. I. K.Albinism. Disponível em: <http://www.emedicine.com/oph/topic3/5.htm.> Acesso em: 16 dez. 2006.

5. CARDEN, S. M. et al. Albinism: modern molecular diagnosis. Br J Ophthalmol, v. 82, n. 2, p. 189-95, 1998.

6. FULLER, B. B.; SPALDING, D.T.; SMITH, D. R. Regulation of the catalytic activity of pre-existing tyrosinase in block and Caucasian human melanocyte cell cultures. Exp Cell Res, v. 262, p. 262, p. 197-208, 2001

7. GENETIKA. Disponível em: <http://www.genetika.com.br>. Acesso em: I I nov. 2006.

8. IOZUMIK, K. et al. Role of tyrosinase as the determinant of pigmentation in cultured human melanocytes. J invest Dermatol, v. I00, p. 806-II, 1993.
9. KING, R. A.; OLDS, D. P. Hairbulb tyrosinase activity in oculocutaneous albinism: Suggestions for pathway control and block location. Am J Med Genet, v. 20, p. 4955, 1985.

I0. KING, R. A.; WITKOP, C. J. Detection of heterozygotes fot tyrosinase-negative oculocutaneous albinism by hairbulb tyrosinase assay. Am J Hum Genet, v. 29, p. 164-8, 1977.

I I.KUGELMAN,T.P.; VAN SCOTT,E.J.Tyrosinase activity in melanocytes of human albinos.J Invest Dermatol, v. 37, p. 73-6, 1961.

12. LEE, S. T. et al. Diverse mutation of the $P$ gene among African-Americans with type II (tyrosinase-positive) oculocutaneous albinism (OCA 2). Hum Mol Genet, v. 3, p. 2047-5I, 1994.

13. LITZ, C. E. et al. Absence of detectable chromosomal and molecular abnormalities in monozygotic twins discordant for the Wiedemann-Beckwith Syndrome. Am J Med Genet, v. 30, n. 3, p. $821-33,1988$.

14. MANGA, P. et al. In Southern Africa, brown oculocutaneous albinism (Boca) maps to the OCA 2 locus on chromosome I5q: P-gene mutations identified. Am J Hum Genet, v. 68, p. 782-7, 2001.

15. OETTING,W. S. et al. Molecular analysis of an extended family type IA (tyrosinase-negative). J Invest Dermatol, v. 97, p. |5-9, $199 \mid$. 
16. OKORO, A. N. Albinism in Nigeria: a clinical and social study. Brit.J. Derm, v. 92, p. 485-92, 1975

17. ONLINE MENDELIAN INHERITANCE IN MAM (OMIM). Disponível em: <http://ncbi.nlm.nih.gov/entrez/query. fcgi? db=OMIM>. Acesso em: 14 out. 2006.

18. PASSOS-BUENO, S. M. R. Ferramentas básicas da genética molecular humana. São Paulo: Atheneu, 2004.

19. RAMSAY et al.The tyrosinase-positive oculocutaneous albinism locus maps to chromosome I $5 q$ | | .2-q | 2. Am J Hum Genet, v. 5 I, p. 879-84, 1992.
20. ROBBINS, S. L. et al. Patologia estrutural e funcional. 4. ed. Rio de Janeiro: Guanabara Koogan, 1991.

2I.STERN, C. Genética humana. Rio de Janeiro: Guanabara Koogan, 1982.

22.STURM,A. S.; BOX, N. F.;TEASDALE, R. D. Human pigmentation genes: identification, structure and consequences of polymorphic variation. Gene, v. 277, n. I-2, p. 49-62, 2001.

23. TREVOR-ROPER, P. D. Marriage of two complete albinos with normally pigmented offspring. Brit J Ophthal, v. 36, p. 107-8, 1952. 